\title{
Utilização do lodo da estação de tratamento de água na produção de mudas de eucalipto
}

Damião Noel Rocha ${ }^{1}$

Antônio Eduardo de Souza²

Leandro Monteiro de Queiroz ${ }^{3}$

Cláudia Aparecida Pontes ${ }^{4}$

\section{Resumo}

Este trabalho teve como objetivo testar a viabilidade de utilização do lodo que se forma na parede dos decantadores e floculadores da ETA na composição do substrato para produção de mudas do híbrido de $E$. urophylla X E. grandis (E. "urograndis"). 0 método de propagação utilizado foi a miniestaquia em tubetes de quatro estrias de $50 \mathrm{~cm}^{3}$. O experimento foi montado em casa de vegetação do viveiro de produção de mudas da CENIBRA no período de março a maio de 2009, em delineamento inteiramente casualizado (DIC), com 11 tratamentos e 4 repetições de 11 plantas. Avaliaram-se a porcentagem de sobrevivência, a altura da parte aérea, o diâmetro do coleto, a matéria seca da parte aérea, a matéria seca da raiz e o comprimento de raiz. O lodo de ETA se mostrou viável como composto de substrato para produção de mudas de $E$. "urograndis" até a proporção de $50 \%$.

Palavras-chave: ETA. Miniestaquia. Propagação assexuada. Urograndis.

\section{Introdução}

A maioria das Estações de Tratamento de Água (ETA) lança seus resíduos diretamente em algum curso d'água próximo ou até mesmo no próprio manancial de captação da estação, podendo causar inconvenientes ambientais como degradação das águas e do ecossistema aquático. Para Franco (2009), os efeitos do lançamento de resíduos gerados no processo de tratamento de água devem ser estudados para se definirem as medidas mitigadoras adequadas. Segundo Cunha et al. (2009), o lodo de ETAs lançado in natura no solo pode causar lixiviação de nitrato, salinização, acúmulo de metais e, quando lançado na água, provoca a elevação da turbidez e da matéria orgânica, resultando na mortandade de organismos aquáticos.

Portella et al. (2003) descrevem que os coagulantes utilizados durante o processo de tratamento de água, os sais de ferro e alumínio, devido às suas cargas, desestabilizam as partículas coloidais em solução, formando flocos com tamanho suficiente para remoção. Segundo Tsutuya e Hirata (2001), esses flocos serão removidos por sedimentação, principalmente nos decantadores, sendo esses resíduos chamados de lodo de ETA.

Para Ribeiro (2004), todo estudo voltado para a caracterização do lodo tem o objetivo de conhecer as suas propriedades físicas e químicas, com o intuito de propor soluções viáveis ao seu reaproveitamento e aplicações sob diferentes formas.

\footnotetext{
1 Instituto Federal Educação, Ciências e Tecnologia de Minas Gerais - campus São João Evangelista, e-mail: damião.rocha@ifmg.edu.br

2 Instituto Federal Educação, Ciências e Tecnologia de Minas Gerais - campus São João Evangelista, e-mail: antonio.souza@ifmg.edu.br

3 Instituto Federal Educação, Ciências e Tecnologia de Minas Gerais - campus São João Evangelista, e-mail: leesilv@hotmail.com

4 Instituto Federal Educação, Ciências e Tecnologia de Minas Gerais - campus São João Evangelista, e-mail: pontesac@gmail.com
} 
Há várias maneiras de gerenciar os resíduos provenientes das ETAs; uma delas refere-se à importância de encontrar alternativas compatíveis com as condições locais; outra, um requisito moderno, diz respeito à necessidade de dispor o lodo de modo econômico e ambientalmente seguro. Os meios efetivos de deposição do lodo consistem naqueles de menor custo, que protejam o meio ambiente e mantenham a segurança operacional por longo período. A seleção da melhor opção ambientalmente praticável envolve a consideração de fatores sociais, econômicos e técnicos (RIBEIRO, 2004).

Segundo Portella et al. (2003), trabalhos voltados para a utilização do lodo de ETA na composição do substrato devem abordar o processo de tratamento da água, pois as características físico-químicas do lodo são influenciadas por ele.

Segundo a Companhia de Saneamento de Minas Gerais (COPASA, 2009), o processo de tratamento de água é composto pelas seguintes fases: coagulação, floculação, decantação, filtração, desinfecção e fluoretação.

De acordo com Figueiredo Neto (2011), o lodo de ETA tem potencial para ser usado na agricultura e silvicultura, destacando a existência de macro e micronutrientes essenciais ao desenvolvimento de plantas. Segundo Portella et al. (2003), o teor de alumínio presente no lodo de ETA é considerado como fator limitante à sua utilização na agricultura.

Este trabalho testou a viabilidade de utilização do lodo que se forma na parede dos decantadores e floculadores de ETA na composição do substrato para produção de mudas do híbrido de $E$. urophylla X E. grandis (E. "urograndis").

\section{Material e Métodos}

0 experimento foi instalado em casa de vegetação do viveiro de produção de mudas da empresa CENIBRA, localizada no município de Belo Oriente - MG, a 19 $13^{\circ}$ '04" de latitude sul e 42 27' $26^{\prime \prime}$ de longitude oeste, próxima à cidade de Ipatinga e da BR-381. Este estudo foi conduzido no período de março de 2009 a maio de 2009. O lodo foi coletado na ETA do IFMG-SJE, no período de fevereiro a dezembro de 2008.

A coleta do lodo foi realizada manualmente, uma vez ao mês, com auxílio de uma pá e baldes plásticos para o transporte e deposição desse lodo em uma caixa de cimento amianto de $1000 \mathrm{~L}$, onde desidratou a pleno sol por 4 a 5 dias. Após este processo, todo o material coletado foi homogeneizado, seco em estufa a $70^{\circ} \mathrm{C}$ por 72 horas. Em seguida, procedeu-se a redução da granulometria do lodo com auxílio de um pilão de madeira e peneira de 10 mesh para padronização. 0 material foi acondicionado em 03 baldes plásticos de $10 \mathrm{~L}$ e enviado à CENIBRA. No viveiro da empresa foram feitas as misturas $(\mathrm{m} / \mathrm{m})$ do lodo ao substrato utilizado por ela na época do experimento (vermiculita, palha de arroz carbonizada e fibra de coco 2/2/1 v/v/v), constituindo assim os tratamentos apresentados na Tabela 1. 
Tabela 1: Diferentes concentrações do substrato utilizado pela CENIBRA (vermiculita, palha de arroz carbonizada e fibra de coco 2/2/1 v/v/v) e do lodo da ETA do IFMG - Campus São João Evangelista.

\begin{tabular}{cc}
\hline Tratamento & Composição (\%) \\
\hline T1 & substrato 100 (testemunha) \\
T2 & substrato $90+$ lodo 10 \\
T3 & substrato $80+$ lodo 20 \\
T4 & substrato $70+30$ de lodo \\
T5 & substrato $60+$ lodo 40 \\
T6 & substrato $50+$ lodo 50 \\
T7 & substrato $40+$ lodo $60 ;$ \\
T8 & substrato $30+$ lodo 70 \\
T9 & substrato $20+$ lodo 80 \\
T10 & substrato $10+$ lodo 90 \\
T11 & lodo 100 \\
\hline
\end{tabular}

Fonte: Elaboração dos autores

Para realizar a mistura, utilizaram-se sacolas plásticas. Cada tratamento foi submetido à análise química no Laboratório de Análises da CENIBRA, onde foram avaliados os teores de Ca, P, K, Mg, Zn, Fé, Mn, Cu, Al, pH e MO.

Usou-se tubete plástico, cilíndrico, com 4 estrias, $33 \mathrm{~mm}$ de diâmetro externo, $27 \mathrm{~mm}$ de diâmetro interno, $125 \mathrm{~mm}$ de altura e $50 \mathrm{~cm}^{3}$ de volume; o enchimento foi manual.

A espécie utilizada foi Eucalyptus urophylla X Eucalyptus grandis, E. "urograndis" (Clone CENIBRA 1274). As estacas com um par de folhas septadas a $1 / 3$ do seu comprimento tiveram as suas bases cortadas em bisel simples e introduzidas em tubetes contendo os substratos listados na tabela 1.

A irrigação e adubação foram feitas de acordo com os procedimentos utilizados pela empresa:

a) irrigação: até 15 dias por aspersão tipo fogger, dos 15 aos 45 dias, por imersão.

b) adubação: superfosfato simples $7 \mathrm{~kg} \mathrm{~m}^{-3}$, sulfato de amônio 0,695 $\mathrm{kg} \mathrm{m}^{-3}$, cloreto de potássio $0,208 \mathrm{~kg} \mathrm{~m}^{-3}$, sulfato de zinco 0,014 $\mathrm{kg} \mathrm{m}^{-3}$, sulfato de cobre 0,014 $\mathrm{kg} \mathrm{m}^{-3}$, sulfato de manganês $0,014 \mathrm{~kg} \mathrm{~m}^{-3}$, ácido bórico $0,021 \mathrm{~kg} \mathrm{~m}^{-3}$; o primeiro foi aplicado de forma direta e os demais, via solução.

Foram avaliados, no sistema radicular, o comprimento e a matéria seca de raízes; na parte aérea, o comprimento, o número de folhas e a matéria seca, aos 45 dias de cultivo.

A sobrevivência das mudas foi avaliada aos 30 dias. A altura da parte aérea e o diâmetro do coleto foram avaliados aos 45 dias. As medidas foram tomadas no ponto de inserção da muda no tubete, usando escala graduada e paquímetro manual.

Após as medições da altura e do diâmetro do coleto e a contagem do número de folhas, as mudas foram acondicionas em sacos de papel, colocadas em uma caixa de isopor e transportadas para o IFMG - SJE, onde foram realizadas as análises de matéria seca e comprimento da raiz. No Instituto, as mudas foram divididas em parte aérea e sistema radicular e colocadas em sacos de papel separados por tratamento. Concomitantemente à separação das partes da muda, foi feita a medição do comprimento de raiz com uma régua graduada.

Para determinação da matéria seca da parte aérea, o material coletado foi seco em estufa a $70^{\circ} \mathrm{C}$, até peso constante, e depois pesado em uma balança de precisão de 0,0001 g. Para determinação da matéria seca de raiz, o material foi seco em temperatura ambiente por 24 horas, para desprendimento do substrato, feito manualmente; os demais procedimentos foram idênticos aos realizados para determinação da matéria seca da parte aérea. 
Foi utilizado o delineamento inteiramente casualizado (DIC), com 4 repetições, de 11 mudas de Eucalyptus urophylla X Eucalyptus grandis, E. "urograndis" (Clone CENIBRA 1274), para cada tratamento. Os dados da sobrevivência, diâmetro do coleto, comprimento da parte aérea e da raiz e número de folhas foram submetidos à análise de variância (ANOVA); aplicou-se o teste Tukey, com nível de significância de 5\%, para avaliar as diferenças entre as médias. As médias de matéria seca da parte aérea e da raiz foram calculadas dividindo-se o peso de todo o tratamento pelo número de repetições, e não medindo cada repetição como nas demais medidas realizadas. Em função disso, seus dados foram trabalhados com estatística descritiva.

Os cálculos estatísticos foram realizados nos softwares SAEG (1993) e MICROSOFT EXCEL ${ }^{\circledR}$ (2000).

\section{Resultados e Discussão}

\section{Composição química dos substratos}

A composição química das misturas utilizadas como substrato em cada tratamento se encontra na Tabela 2. Observa-se que o teor de alumínio foi maior na testemunha que nas misturas contendo lodo de ETA e até mesmo no substrato composto unicamente pelo lodo. As baixas concentrações de alumínio no lodo, alcançadas no presente estudo, divergem dos valores encontrados por Figueiredo Neto (2011). Esta diferença se deve provavelmente a metodologia de coleta, uma vez que no presente estudo foi coletado apenas o lodo que se forma na parede dos floculadores e do decantador e não o associando ao lodo depositado no fundo do decantador onde se acredita que a concentração de alumínio seja alta.

Tabela 2: Resultado da análise química dos substratos utilizados nos tratamentos com variação de $10 \%$ na concentração de lodo de 0\% (T1) a 100\% (T11)

\begin{tabular}{|c|c|c|c|c|c|c|c|c|c|c|c|c|}
\hline Trat. & $\begin{array}{c}\mathrm{pH} \\
\text { em } \\
\text { Água }\end{array}$ & $\begin{array}{l}\text { Matéria } \\
\text { Orgânica }\end{array}$ & $P$ & K & $\mathrm{Ca}$ & $\mathrm{Mg}$ & Al & $\mathrm{Zn}$ & $\mathrm{Cu}$ & $\mathrm{Fe}$ & $\mathrm{Mn}$ & $\begin{array}{c}P \\
\text { Reman. }\end{array}$ \\
\hline & $1: 2,5$ & $\begin{array}{c}\text { dag } \\
\mathrm{dm}^{-3}\end{array}$ & $\begin{array}{c}\mathrm{mg} \\
\mathrm{dm}^{-3}\end{array}$ & $\begin{array}{c}\mathrm{mg} \\
\mathrm{dm}^{-3}\end{array}$ & $\begin{array}{l}\mathrm{Cmol}_{\mathrm{c}} \\
\mathrm{dm}^{-3}\end{array}$ & $\begin{array}{l}\mathrm{Cmol}_{\mathrm{c}} \\
\mathrm{dm}^{-3}\end{array}$ & $\begin{array}{l}\mathrm{Cmol}_{\mathrm{c}} \\
\mathrm{dm}^{-3}\end{array}$ & $\begin{array}{c}\mathrm{mg} \\
\mathrm{dm}^{-3}\end{array}$ & $\begin{array}{c}\mathrm{mg} \\
\mathrm{dm}^{-3}\end{array}$ & $\begin{array}{c}\mathrm{mg} \\
\mathrm{dm}^{-3}\end{array}$ & $\begin{array}{c}\mathrm{mg} \\
\mathrm{dm}^{-3}\end{array}$ & $\begin{array}{c}\mathrm{mg} \\
\mathrm{dm}^{-3}\end{array}$ \\
\hline $\mathrm{T} 1$ & 6,51 & 6,06 & 845,88 & 1018 & 13,22 & 1,87 & 0,95 & 10,54 & 5,261 & 31 & 37,7 & 78,7 \\
\hline T2 & 6,38 & 9,88 & 440,16 & 956 & 14,13 & 0,97 & 0,19 & 9,86 & 4,214 & 67 & 82,8 & 42,5 \\
\hline T3 & 6,37 & 5,57 & 549,45 & 1143 & 13,60 & 8,42 & 0,03 & 13,98 & 4,455 & 71 & 162,1 & 26,4 \\
\hline T4 & 6,44 & 5,52 & 384,09 & 940 & 11,28 & 7,44 & 0,01 & 12,08 & 3,322 & 71 & 197,5 & 21,2 \\
\hline T5 & 6,52 & 5,52 & 235,49 & 769 & 10,16 & 6,60 & 0,06 & 10,09 & 2,627 & 79 & 250,0 & 11,8 \\
\hline T6 & 6,61 & 4,13 & 181,45 & 504 & 9,97 & 6,10 & 0,04 & 9,57 & 2,248 & 89 & 345,4 & 13,9 \\
\hline T7 & 6,69 & 5,21 & 77,39 & 737 & 8,49 & 5,30 & 0,09 & 8,61 & 1,366 & 89 & 351,9 & 4,5 \\
\hline T8 & 6,75 & 6,94 & 36,60 & 566 & 8,41 & 4,08 & 0,01 & 7,66 & 1,080 & 66 & 560,3 & 3,1 \\
\hline T9 & 6,81 & 9,68 & 13,13 & 172 & 6,72 & 3,13 & 0,03 & 5,04 & 0,507 & 55 & 701,4 & 0,6 \\
\hline T10 & 6,81 & 9,06 & 3,61 & 303 & 4,54 & 1,83 & 0,02 & 4,35 & 0,270 & 50 & 753,5 & 0,0 \\
\hline T11 & 6,89 & 11,04 & 0,25 & 53 & 3,06 & 0,40 & 0,03 & 2,79 & 0,192 & 44 & 601,3 & 0,0 \\
\hline
\end{tabular}

Fonte: Elaboração dos autores.

\section{Sobrevivência}

A porcentagem média de sobrevivência das estacas foi de 85,41\%, avaliada aos 30 dias, bem mais alta que as encontradas por Freitas et al. (2006), sobrevivência de 71,5\%, com clones de $E$. 
grandis avaliadas aos 40 dias. Como mostra a Figura 1, o tratamento T9 (substrato $20 \%+$ lodo 80\%) foi o que apresentou melhor resultado, com 95,83\% de sobrevivência, e com menor potencial se encontra o tratamento T3 (substrato $80 \%$ + lodo 20\%) com 77,08\%. De maneira geral, o comportamento foi homogêneo em todos os tratamentos, com desvio padrão de 4,9\%. Essa homogeneidade e os altos índices de sobrevivência podem ser reflexos do tipo de propagação utilizada no experimento, que tem por característica a homogeneidade das mudas e o alto índice de porcentagem de sobrevivência do clone utilizado, em torno de $90 \%$.

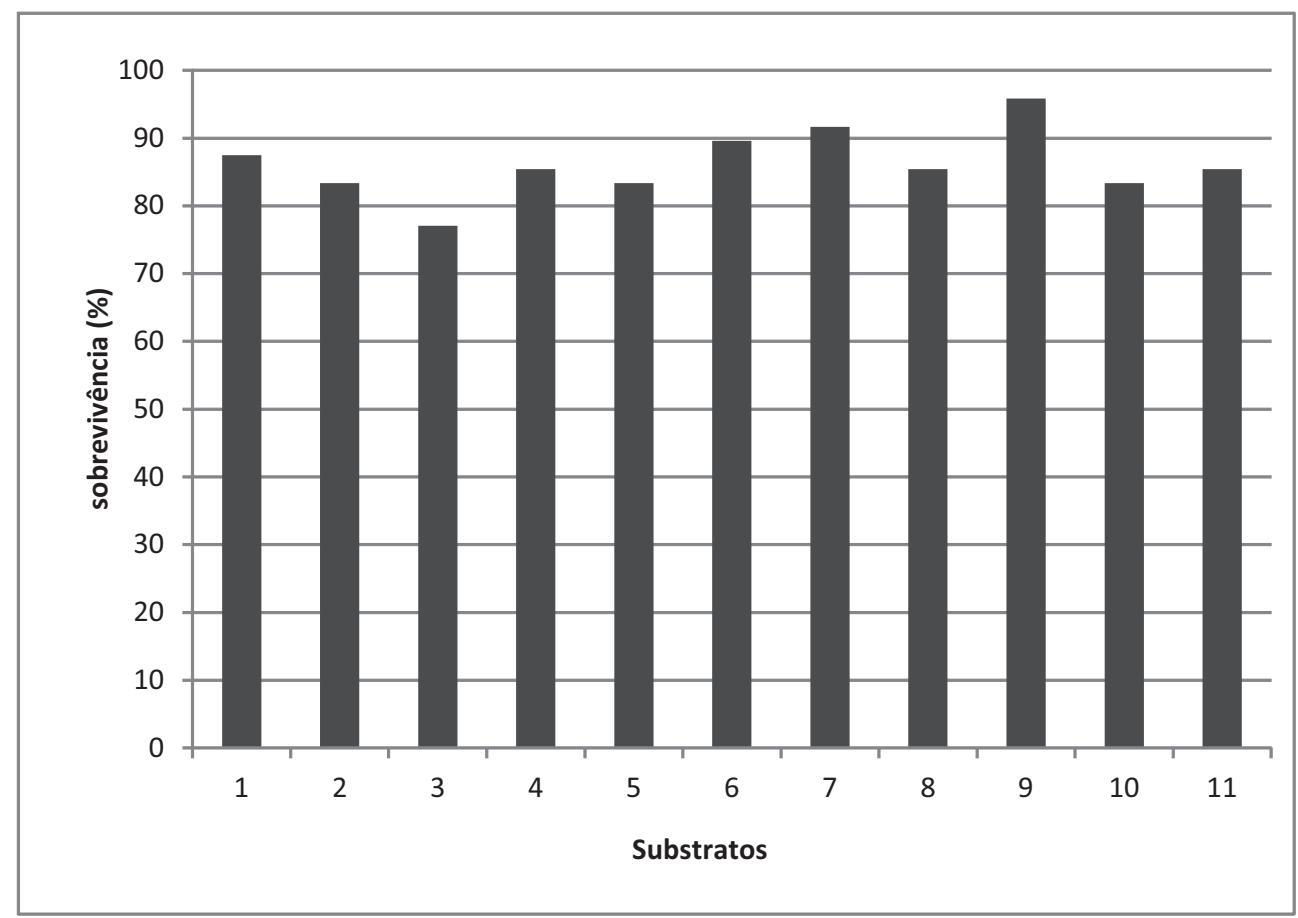

Figura 1: Porcentagem de sobrevivência das estacas de Eucalyptus "urograndis" em substratos com diferentes concentrações de lodo de ETA.

Fonte: Elaboração dos autores.

\section{Parte aérea}

Conforme apresentado na Tabela 3, quanto à altura da parte aérea apenas os tratamentos T9, T10 e T11 diferiram da testemunha que teve os melhores resultados com uma média de 20,16 cm. Pode-se atribuir a esses resultados tão homogêneos à composição química dos substratos formados da mistura do lodo até a concentração de $70 \%(\mathrm{~m} / \mathrm{m})$ por apresentar características muito parecidas com a do substrato utilizado pela CENIBRA (T1). Os índices de incremento em altura dos tratamentos T1 ao T9 foram superiores aos valores encontrados por Maeda et al. (2007) que, trabalhando com muda de $E$. badjensis avaliados aos 103 dias após semeadura, conseguiram 18,2 cm como melhor resultado, Lopes (2005) trabalhando com mudas de $E$. urophylla avaliadas aos 90 dias encontrou média de 18,23 cm. Essa superioridade pode ser advinda da diferença entre a espécie trabalhada pelos autores citados e a utilizada no presente estudo, além desses autores terem utilizado mudas de origem seminífera. 
Tabela 3: Altura da parte aérea das mudas de E. "urograndis" em centímetros submetidas às diversas concentrações de lodo de ETA

\begin{tabular}{ccc}
\hline TRATAMENTO & MEDIAS & \\
\hline 1 & 20,1650 & A \\
2 & 19,1617 & A B \\
4 & 19,0735 & A B \\
6 & 18,9744 & A B \\
5 & 18,7105 & A B \\
8 & 18,3650 & A B \\
7 & 18,1850 & A B \\
3 & 18,1461 & A B \\
9 & 17,2429 & B C \\
10 & 14,5552 & C D \\
11 & 11,0960 & D \\
\hline
\end{tabular}

Médias seguidas pelas mesmas letras não diferem estatisticamente entre si ao nível de $5 \%$ de significância pelo teste Tukey. Fonte: Elaboração dos autores.

Alguns dos tratamentos que tiveram incremento em altura entre os menores, como o T9, apresentaram bom desenvolvimento do diâmetro do coleto alcançando bons índices.

A melhor média de diâmetro do coleto novamente foi do T1 que se diferiu apenas do T7, T10 e T11(Tabela 4). Os diâmetros do coleto encontrados foram pouco inferiores aos encontrados por Krolow (2007), média de 2,48, que trabalhou com mudas seminíferas de $E$. grandis avaliadas aos 90 dias, e por Lopes (2005), média de 2,34, trabalhando com mudas seminíferas de E. urophylla avaliadas também aos 90 dias.

Tabela 4: Diâmetro do coleto das mudas de $E$. "urograndis" em milímetro submetidas às diversas concentrações de lodo de ETA

\begin{tabular}{ccc}
\hline TRATAMENTO & MEDIAS & \\
\hline 1 & 2,3575 & A \\
4 & 2,1730 & A B \\
2 & 2,1583 & A B \\
9 & 2,1524 & A B \\
3 & 2,1485 & A B \\
6 & 2,1306 & A B \\
5 & 2,1158 & A B \\
8 & 2,1125 & A B \\
7 & 2,0625 & B C \\
10 & 1,9655 & B C \\
11 & 1,7760 & C \\
\hline
\end{tabular}

Médias seguidas pela mesma letra não diferem estatisticamente ao nível de $5 \%$ de significância pelo teste Tukey.

Fonte: Elaboração dos autores.

Quanto ao peso da matéria seca da parte aérea, conforme apresentado na Figura 2, a meIhor média desse parâmetro é do tratamento T1 com 0,6795 g/muda e o menor rendimento foi do tratamento T11 com 0,2879 g/muda. A média geral foi de 0,5505 g/muda com desvio padrão de 0,1088 g/muda, indicando uma variabilidade de 19,76\%. A média geral esteve próxima dos valores encontrados por Freitas et al. (2006), média de 0,5133 g/muda, em mudas clonais de E. grandis, utilizando tubes $50 \mathrm{cc}$, com 90 dias. 


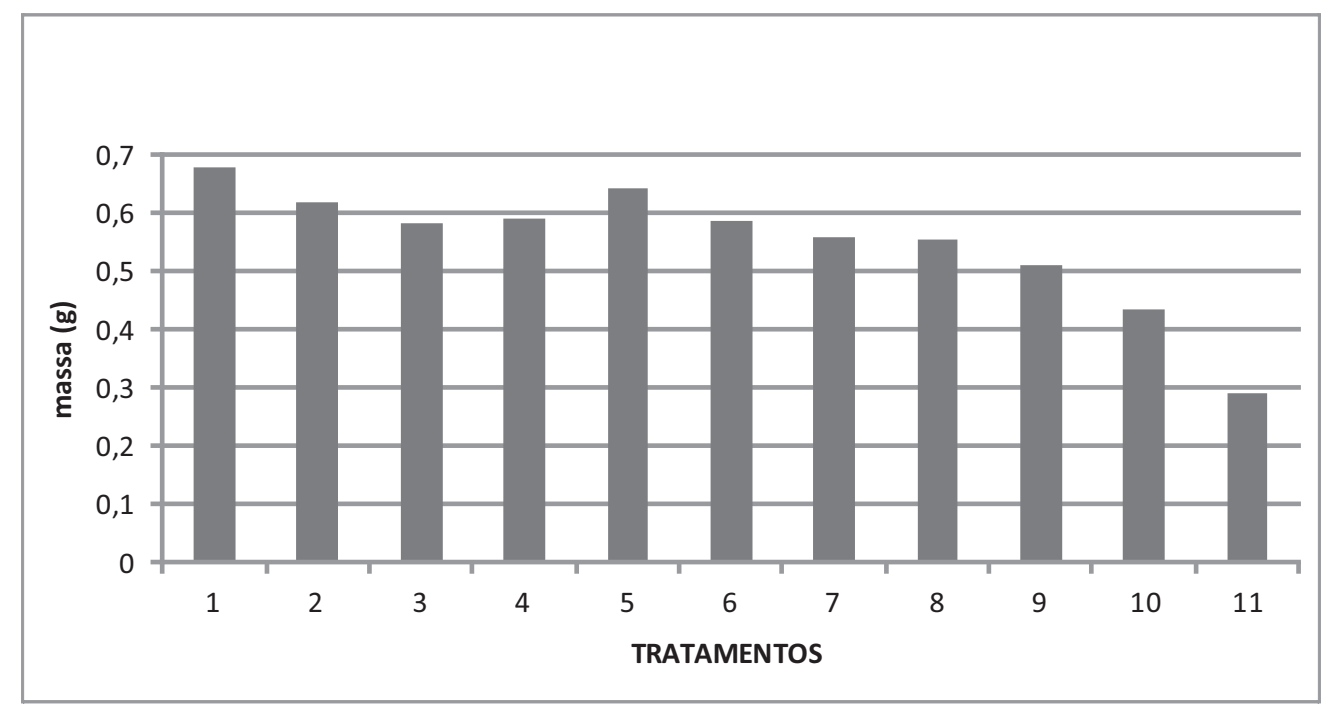

Figura 2: Matéria seca da parte aérea (g/muda) das mudas de E. "urograndis" em substratos com diferentes concentrações de lodo de ETA.

Fonte: Elaboração dos autores.

\section{Sistema radicular}

Quanto ao comprimento de raiz, o tratamento T11 teve resultado inferior aos demais que não apresentaram diferença significativa entre si (Tabela 5). Essa igualdade pode ser atribuída ao fato de os recipientes utilizados no experimento terem impedido que as mudas emitissem raízes além de sua extensão, uma vez que aquelas que conseguem ultrapassar seu tamanho são oxidadas, cessando seu crescimento pela ação do oxigênio presente no ar. O tratamento T11 teve uma média menor porque, provavelmente, o substrato com 100\% de lodo pode ter oferecido uma maior resistência física à penetração da raiz.

Tabela 5: Comprimento de raiz das mudas de $E$. "urograndis" em centímetros submetidas às diversas concentrações de lodo de ETA

\begin{tabular}{|c|c|}
\hline TRATAMENTO & MEDIAS \\
\hline 1 & 11,4875 \\
\hline 9 & 11,4762 \\
\hline 2 & 11,2500 \\
\hline 8 & 11,1550 \\
\hline 5 & 11,1184 \\
\hline 3 & 11,0455 \\
\hline 7 & 10,9375 \\
\hline 6 & 10,3472 \\
\hline 4 & 10,3378 \\
\hline 10 & 9,6552 \\
\hline 11 & 6,6200 \\
\hline
\end{tabular}

Médias seguidas pela mesma letra não diferem estatisticamente ao nível de $5 \%$ de significância pelo teste tukey. Fonte: Elaboração dos autores.

Resultados de matéria seca de raiz mostram um comportamento diferente dos demais parâmetros, nos quais o tratamento T1 apresentou sempre os melhores resultados. Nesse parâmetro, os melhores resultados foram obtidos nos tratamentos T8 (substrato 30\% + lodo 70\%), T7 (substrato 
40\% + lodo 60\%) e T6 (substrato 50\% + lodo 50\%); com 0,359 g/muda; 0,3335 g/muda e 0,3125 $\mathrm{g} /$ muda, respectivamente; o tratamento T11 foi o que apresentou menor média com 0,11 g/muda (Figura 3). Os valores encontrados em todos os tratamentos, exceto o T10 e T11, foram semelhantes aos observados por Lopes (2005), com média de 0,26g, trabalhando com mudas de E. urophylla, avaliadas aos 90 dias após a semeadura; e os tratamentos T6, T7 e T8, próximos aos encontrados por Andrade et al. (2010), com média de 0,33g, que trabalharam com mudas seminíferas de $E$. urograndis.

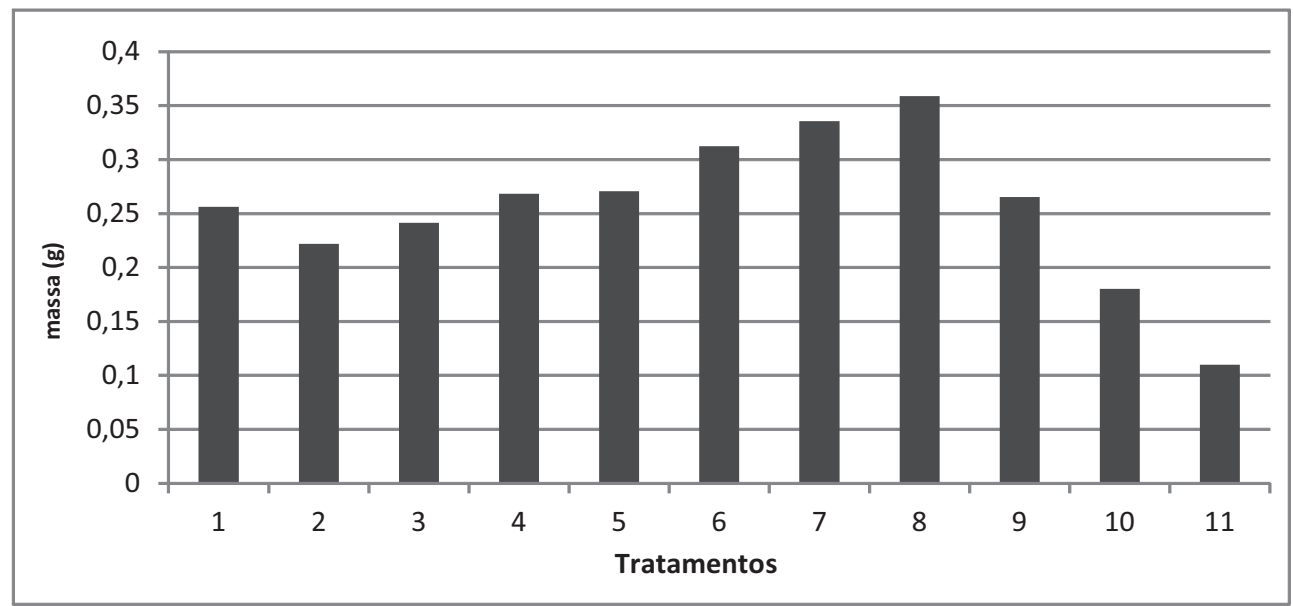

Figura 3: Matéria seca da raiz (g/muda) das mudas de E. "urograndis" em substratos com diferentes concentrações de lodo de ETA.

Fonte: Elaboração dos autores.

\section{Conclusão}

De acordo com os resultados encontrados nos parâmetros testados, a utilização do lodo que se forma nas paredes dos floculadores e decantadoes de ETA, como parte do composto de substrato na produção de mudas de $E$. "urograndis", é viável, do ponto de vista técnico, econômico e ambiental, em concentrações até $50 \%$, tornando-se assim uma alternativa para utilização desse lodo, o que evitaria sua deposição nos cursos d'água.

\section{Agradecimentos}

À Celulose Nipo Brasileira (CENIBRA), pela viabilização da instalação do experimento na estação experimental da empresa, bem como pelos apoios técnicos.

\section{Use of sludge from the water treatment plant for production of seedlings of Eucalipto}

\section{Abstract}

The objective of this study is to test the feasibility of using the sludge that forms on decanter and floculater walls of the Water Treatment Plant (WTP) in the composition of substrate for production of $E$. urophylla x $E$. grandis (E. "urograndis") hybrid seedlings. The method of propagation used was 
minicutting in four $50 \mathrm{~cm}^{3}$ streaks tubes. The experiment was carried out in CENIBRA greenhouse under nursery conditions from March to May 2009, in a completely randomized design (CRD), with 11 treatments and 4 replications of 11 plants each. The percentage of rooting, the height of the shoot, stem diameter, dry matter of shoot, dry matter of roots and root length were evaluated. The WTP sludge can be applied as a substrate compound for E. "urograndis" seedlings production up to a rate of $50 \%$.

Keywords: WTP. Minicutting. Assexual propagation. Urograndis.

\section{Referências}

ANDRADE, F. R.; SILVA, R. B. G.; SIMOES, D.; SILVA, Magali Ribeiro da . Eficiência da aplicação de fertilizante de liberação controlada em mudas seminais de Eucalyptus urograndis em diferentes substratos. In: CONGRESSO DE INICIAÇÃO CIENTÍFICA DA UNESP, n.22, 2010, Botucatu. Anais... Botucatu, 2010.

ANDREOLI, C.V. (Coord.) Resíduos sólidos do saneamento: processamento, reciclagem e disposição final. Rio de Janeiro: RiMa / ABES / PROSAB, 2001.

CUNHA, A. B. L. da; LAGES, F. A. E.; MACHADO, A. O. V.; SOARES, A. F. S. Orientações básicas acerca do impacto do lodo gerado nas ETAs, alternativas de tratamento/disposição e legislação correlata. Belo Horizonte: Ministério Público do Estado de Minas Gerais. Procuradoria Geral de Justiça. Central de apoio técnico, 2009.

COMPANHIA DE SANEAMENTO DE MINAS GERAIS. Tratamento da água. Acesso em: 29 de abril de 2009. Online. Disponível em: http://www.copasa.com.br/cgi/cgilua.exe/sys/start.htm?sid=98.

FIGUEIREDO NETO, A. Utilização de lodo de estação de tratamento de água na produção de mudas de árvores com ocorrência no cerrado. 2011. 97p. Dissertação (Mestrado em Engenharia do Meio Ambiente) - Universidade Federal de Goiás.

FRANCO, E.S. Avaliação da influência dos coagulantes sulfato de alumínio e cloreto férrico na remoção de turbidez e cor da água bruta e sua relação com sólidos na geração de lodo em estações de tratamento de água. 2009. 187p. Dissertação (Mestrado em Engenharia Ambiental) - Universidade Federal de Ouro Preto, Ouro Preto-MG.

FREITAS. T. A. S. de.; BARROSO, D. G.; CARNEIRO, J. G. A.; PENCHEL, R. M.; FIGUEIREDO, F. A. M. M. A. Mudas de eucalipto produzidas a partir de miniestacas em diferentes recipientes e substratos. Revista Árvore, Viçosa-MG, v.30, n. 4, p. 519-528, 2006.

KROLOW, I. R. C. Produção de mudas de eucalipto em substratos obtidos a partir de resíduos agroindustriais, compostados e vermicompostados. 2007. 74p. Dissertação (Mestrado em Produção Vegetal) - Faculdade de Agronomia Eliseu Maciel, Universidade Federal de Pelotas. Pelotas.

LOPES, E.D. Qualidade de mudas de Eucalyptus urophylla, E. camaldulensis e E. citriodora produzidas em blocos prensados e em dois modelos de tubetes e seu desempenho no campo. 2005. 83p. Dissertação (Mestrado em Agronomia) - Universidade Estadual do Sudoeste da Bahia. 
MAEDA, S.; DEDECEK, R. A.; AGOSTINI, R. B.; ANDRADE, G. C.; SILVA, H. D. da; Caracterização de substratos para produção de mudas de espécies florestais elaborados a partir de resíduos orgânicos. Pesquisa Agropecuária Brasileira, Colombo, n.54, p.97-104, 2007.

MICROSOFT EXCEL. Microsoft Corporation. Versão 7. 2000.

PORTELLA, K. F.; ANDREOLI, C. V.; HOPPEN, C.; SALES, A.; BARON, O. Caracterização físico química do lodo centrifugado da Estação de Tratamento de Água Passauna - Curitiba, PR. In: CONGRESSO BRASILEIRO DE ENGENHARIA SANITÁRIA E AMBIENTAL, 22, 2003, Joinvile. Anais... Joinvile: ABES, 2003.

RIBEIRO, F. L. M. Estudo das águas residuárias da ETA de Itabirito, MG: caracterização e alternativas de tratamento e reutilização. Ouro Preto - MG: UFOP, 2004.

SAEG - Sistema para Análises Estatísticas. Viçosa: UFV. Fundação Arthur Bernardes. Versão 5.0. 1993

TSUTUYA, M. T.; HIRATA, A. Y. Aproveitamento e Disposição Final de Lodos de Estação de Tratamento de Água do Estado de São Paulo. In: CONGRESSO BRASILEIRO DE ENGENHARIA SANITÁRIA E AMBIENTAL, 21. 2001, João Pessoa. Anais... João Pessoa: ABES, 2001.

\section{Histórico editorial}

Submetido em: 20/08/2013

Aceito em: 30/10/2014 